\title{
Generalised non-reactive tuberculosis: a clinicopathological study of four patients
}

\author{
RAJUL SINGH, RAMESH C JOSHI, JOHN CHRISTIE
}

From the Departments of Histopathology and Chest Medicine, Manor Hospital, Walsall, and the Department of Histopathology, Russells Hall Hospital, Dudley

ABSTRACT Non-reactive tuberculosis is a histopathological entity characterised by foci of necrosis surrounded by normal parenchyma and absence of epithelioid cell granulomas. The clinicaks presentation and necropsy findings in four patients are described and the pathogenesis of the diseaseo discussed.

\section{Introduction}

Non-reactive tuberculosis was first described in 1891 by Landouzy, ${ }^{1}$ who called it "typhobacillosis." It subsequently appeared in publications under various names until 1954, when O'Brien ${ }^{2}$ reviewed 66 reported cases and suggested the term by which it is now known. He defined it as a "fatal form of tuberculosis in which many organs contain miliary foci of necrosis surrounded by normal parenchymal cells." ${ }^{2}$ The lesions are softer than the classical miliary tubercle, contain many acid fast bacilli, and show little cellular response.

This condition has been reported in association with the acquired immunodeficiency syndrome (AIDS), malignant lymphoma, and haematological abnormalities such as chronic leukaemia, anaemia, pancytopenia, agranulocytosis, polycythyaemia, myelosclerosis, and leukaemoid reactions. ${ }^{2-8}$ We present four cases that occurred in the absence of any haematological disease.

\section{Case reports}

\section{PATIENT 1}

A 78 year old retired foundry worker presented to his general practitioner with a history of productive cough, dyspnoea and chest pain of several weeks' duration. He had had asthma for 20 years and had been taking prednisolone $30 \mathrm{mg}$ daily for 11 weeks. On examination there were crackles at the lung bases; the liver and spleen were not enlarged. A chest infection was diagnosed and treatment with amoxycillin was

Address for reprint requests: Dr $\mathrm{R}$ Singh, Department of Histopathology, Manor Hospital, Walsall WS2 9PS

Accepted 10 August 1989

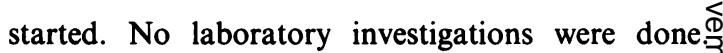
Thirteen days later he died at home.

At necropsy there were areas of consolidation in the right lung and both lungs contained a few soft $\overrightarrow{0}$ yellowish subpleural abscesses up to $0.5 \mathrm{~cm}$ in diameter. There was no evidence of old tuberculosis. The liver, spleen, and kidneys were normal.

\section{PATIENT 2}

A 53 year old black man presented with a two montho history of cough, breathlessness, malaise, intermitten? fever, and weight loss. On examination he was undero nourished and there was hepatomegaly and dullness a? the right lung base. A chest radiograph showed bilateral miliary mottling and a right basal pleural. shadow. He was slightly anaemic and liver function $\overrightarrow{\delta^{*}}$ were abnormal (table). Two blood cultures were negative. He died suddenly 72 hours after admission..$\dot{-}$

At necropsy both lungs contained numerous microabscesses, there was a right sided fibrinous pleural effusion, and hilar and paratracheal lymph nodes were enlarged. The liver, spleen and kidneys were normal.

\section{PATIENT 3}

A 65 year old housewife was admitted with shortnes of breath. She had diabetes controlled with diet $\mathrm{N}$ Physical examination revealed signs of mitral stenosi and incompetence, rapid atrial fibrillation and conges $\omega$ tive cardiac failure. A chest radiograph showed gross cardiomegaly, pulmonary oedema, and bilateraf pleural effusions. There was a neutrophil leucocytosi and liver function tests gave abnormal results (table): She improved with treatment and was discharged home. She was readmitted one month later with malaise and hepatomegaly, but no respiratory symp $\frac{\text { ? }}{\mathrm{P}}$ toms. Twenty four hours later she became drowsy? 
Results of haematological and biochemical investigations in cases 2-4 with normal reference values

\begin{tabular}{|c|c|c|c|c|}
\hline Investigation & Normal & Case 2 & Case 3 & Case 4 \\
\hline \multicolumn{5}{|c|}{ Haematological } \\
\hline $\begin{array}{l}\text { Haemoglobin }(\mathrm{g} / \mathrm{l}) \\
\text { White cells }\left(\times 10^{9} / \mathrm{l}\right) \\
\text { Neutrophils }(\%)\end{array}$ & $\begin{array}{c}130-180 \\
4-11 \\
40-75\end{array}$ & $\begin{array}{c}111 \\
6 \cdot 2 \\
74\end{array}$ & $\begin{array}{l}152 \\
11 \cdot 3 \\
88\end{array}$ & $\begin{array}{c}117 \\
6 \cdot 8 \\
78\end{array}$ \\
\hline $\begin{array}{l}\text { Erythrocyte sedimentation rate } \\
\text { (mm in first hour) }\end{array}$ & $3-5$ & 7 & 3 & 8 \\
\hline \multicolumn{5}{|c|}{ Biochemical } \\
\hline Sodium $(\mathrm{mmol} / \mathrm{l})$ & $134-152$ & 127 & 121 & 128 \\
\hline Potassium $(\mathrm{mmol} / \mathrm{l})$ & $3 \cdot 4-5 \cdot 6$ & 3.6 & $4 \cdot 7$ & $3 \cdot 5$ \\
\hline Urea $(\mathrm{mmol} / \mathrm{l})$ & $1 \cdot 7-8 \cdot 3$ & $9 \cdot 5$ & 9.9 & $4 \cdot 3$ \\
\hline Creatinine $(\mu \mathrm{mol} / \mathrm{l})$ & $65-165$ & 63 & 91 & - \\
\hline Alkaline phosphatase (KAU/dl) & $7-25$ & 156 & 50 & 51 \\
\hline Total protein $(\mathrm{g} / \mathrm{l})$ & $62-82$ & 52 & 61 & 69 \\
\hline Albumin $(\mathrm{U} / \mathrm{l})$ & $36-52$ & 24 & 33 & 32 \\
\hline Alanine aminotransferase $(\mathrm{U} / \mathrm{l})$ & $0-40$ & 95 & - & 26 \\
\hline$\gamma$-Glutamyltransferase $(\mathrm{U} / \mathrm{l})$ & $10-48$ & 202 & 77 & 86 \\
\hline \multicolumn{5}{|l|}{ Bilirubin $(\mu \mathrm{mol} / \mathrm{l})$} \\
\hline Total & $1-19$ & 28 & 25 & 14 \\
\hline Direct & $0-12$ & 11 & - & 1 \\
\hline Indirect & $0-15$ & 17 & - & 13 \\
\hline
\end{tabular}

restless, and febrile, and developed basal lung crackles. A chest radiograph showed diffuse miliary mottling. The cerebrospinal fluid was normal. She was given $300 \mathrm{mg}$ of hydrocortisone intravenously and antituberculous treatment was started, but she died the same day. Cultures of gastric washings were negative for Mycobacterium tuberculosis.

At necropsy there were multiple subpleural abscesses in the lung up to $0.1 \mathrm{~cm}$ in diameter, but no abnormality of the liver, spleen, kidneys, or hilar lymph nodes.

\section{PATIENT 4}

An 81 year old Asian man, a retired foundry worker, presented with a history of cough, anorexia, weight loss and intermittent pyrexia of four months' duration. He had been treated for asthma for 10 years with $5 \mathrm{mg}$ of prednisolone daily. On examination he was febrile and wasted, with wheezes and crackles in both lungs. The liver was not enlarged. A chest radiograph showed diffuse reticular and nodular shadows in the upper and mid zones of both lungs. There was no haematological abnormality, but liver function tests gave abnormal results (table). He was treated with conventional antibiotics. Four weeks later he became confused and drowsy, and developed signs of meningeal irritation. A chest radiograph showed little change but acid fast bacilli were found in the sputum. Cerebrospinal fluid examination showed: protein 2.91 $\mathrm{g} / \mathrm{l}$, glucose $0.7 \mathrm{mmol} / 1$, total cell count $10 \times 10^{9} / 1$ with $60 \%$ neutrophils, $30 \%$ lymphocytes, and $10 \%$ tissue cells. Ziehl-Neelson staining was negative, but a few rhodamine-auramine positive organisms were present. Antituberculous drugs and intravenous hydrocortisone $100 \mathrm{mg}$ twice daily were given. His condition improved initially, but he died suddenly five weeks later.

A limited necropsy showed focal collections of pus and meningeal thickening at the base of the brain. The lower lobes of both lungs had areas of consolidation and bronchi contained pus. The hilar lymph nodes were enlarged and soft.

\section{Histological findings}

In the lungs in each case there were numerous necrotic foci containing nuclear debris and large numbers of acid fast bacilli (figs 1 and 2). The lesions were surrounded by normal lung parenchyma except in case 3 , where there was a peripheral zone of hyperaemia and polymorph neutrophil infiltration. No epithelioid cell granulomas were present, though there were occasional Langhans cells in cases 1 and 4 . Similar foci were seen in the hilar lymph nodes in all cases except for patient 3 , where the hilar lymph nodes were normal. The liver, spleen, and kidneys were affected in patients 2 and 3 , the adrenals and uterus in patient 3 , and the brain and meninges in patient 4 . Lesions in the kidneys were usually centred on glomeruli. Very occasional epithelioid cell granulomas were present in the extrapulmonary organs of patient 3 . In all cases culture confirmed the presence of $M$ tuberculosis (human type).

\section{Discussion}

Since 1954100 cases of non-reactive tuberculosis have been published. It presents as an overwhelming acute infection with pyrexia, splenomegaly, and sometimes hepatomegaly. Chest radiographs show fine miliary mottling, which is not always conspicuous, ${ }^{2-7}$ and results of liver function tests may be abnormal. ${ }^{45}$ Haematological abnormalities are common, and haematological malignancy may be present. ${ }^{235-7}$

The term "cryptic disseminated tuberculosis" is applied to both non-reactive and reactive forms of tuberculosis when there is no clinical or radiological evidence of the disease. ${ }^{8}$ It is rapidly fatal and is diagnosed only at necropsy. The disease in our patients was disseminated and fatal but could not be labelled "cryptic." All four had pyrexia and respiratory symptoms, and chest radiographs showed miliary mottling in three, (one patient did not have chest radiography).

The lung lesions in this condition differ from those of other types of tuberculosis in that there is no cavitation or fibrosis. The lesions are up to $0.5 \mathrm{~cm}$, and are softer than classical miliary tubercles. ${ }^{2}$ In two of our patients there were also yellowish white subpleural nodules resembling staphylococcal abscesses, and in one there was tuberculous meningitis, a complication 


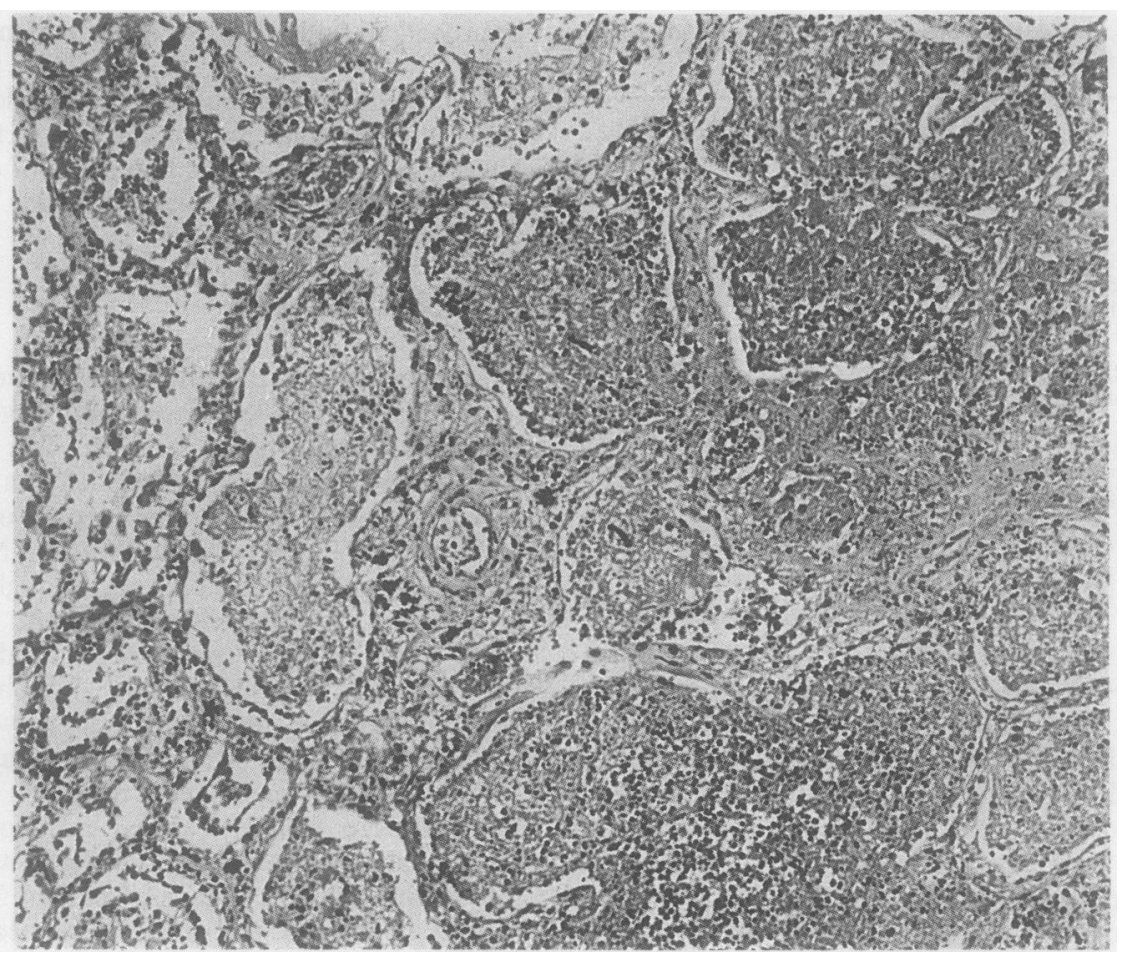

Fig 1 Section of lung showing numerous discrete foci of necrosis surrounded by normal parenchyma. Note absence of Langhans' giant cells and epithelioid cell granulomas. (Haematoxylin and eosin.)

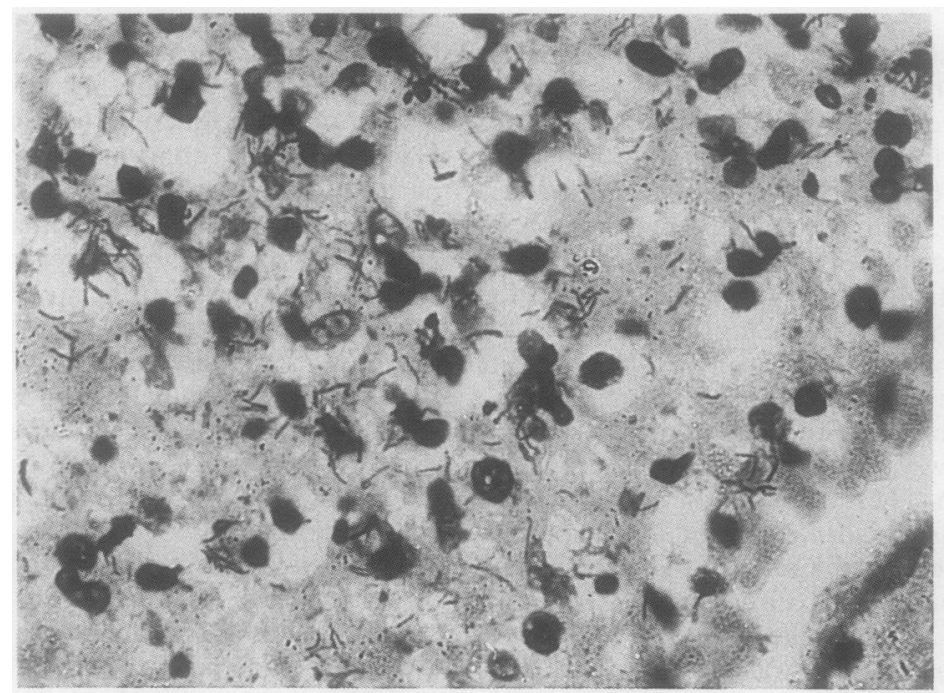

Fig 2 Section of lung showing numerous acid fast bacilli in a necrotic focus. (Ziehl-Neelson.) 
not previously described. Histologically, the lesions are structureless and necrotic, contain numerous acid fast bacilli, and are surrounded by normal lung parenchyma.

The lack of cellular response suggests defective $T$ cell function. Deficiency of cell mediated immunity has been found in patients with non-reactive tuberculosis, ${ }^{9}$ and most reported cases have been in patients with the acquired immune deficiency syndrome, lymphoma, or haematological disease. There was no evidence of any such disease in our patients, though one patient was diabetic, three were elderly, and two were having long term corticosteroid treatment for asthma. The number of circulating $\mathrm{T}$ lymphocytes falls with age and their phytohaemagglutinin transformation is reduced ${ }^{10}$; in diabetic patients cell mediated immunity is depressed ${ }^{10}$ and hyperglycaemia favours multiplication of organisms. ${ }^{10}$ Corticosteroids inhibit fibrosis and the formation of granulation tissue $^{12}$ as well as affecting $T$ lymphocyte and monocyte function, neutrophil chemotaxis, and the release of lymphokines and lysozymes. ${ }^{13}$ The entry of large numbers of organisms into the circulation may also be a factor, as an intravenous injection of a heavy inoculum of mycobacteria has been shown to result in persistent suppression of immunity ${ }^{14}$ Antigenic load seems to be more important than the viability of the organisms. ${ }^{15}$ As in lepromatous leprosy, immunological unresponsiveness allows the organisms to multiply and invade tissue in large numbers. ${ }^{14}$

Live mycobacteria and cell wall peptidoglycolipids both trigger the release of tumour necrosis factor, ${ }^{16}$ and the necrosis characteristic of this condition is probably due to release of this substance by lymphokine activated macrophages. The high mortality in non-reactive tuberculosis could also be attributed to tumour necrosis factor, as mice with damaged livers are extremely susceptible to its lethal effects. ${ }^{17}$ It has been postulated that patients with liver disease and tuberculosis who die soon after starting chemotherapy do so because of the combined hepatotoxic effects of rifampicin and tumour necrosis factor, which is activated by components of the rapidly killed bacteria. ${ }^{16}$ Three of our patients had abnormal results in liver function tests, and two had hepatomegaly.

In non-reactive tuberculosis there is an increased risk of infection for those coming in contact with the patient, particularly the pathologists who perform the necropsy. The condition has seldom been recognised before death, the appearance of the lesions is atypical, and the affected tissues contain a large number of organisms. Non-reactive tuberculosis should be considered in patients with pyrexia, an abnormal chest radiograph, haematological abnormalities, or defective immunity. Sputum, fasting gastric contents, and liver biopsy material should be examined for tubercle bacilli. The tuberculin reaction is usually negative and hence unlikely to be helpful. ${ }^{25}$ As early confirmation of the diagnosis may be difficult or impossible, antituberculous chemotherapy should be started as soon as the disease is suspected.

We thank the staff of the histology department for their technical assistance. We also thank the staff of the photographic department and Miss G Dodd for typing the manuscript.

\section{References}

1 Landouzy L. De la fievre bacillaire pretuberculeure a forme typhoide. Typhobacillose. Sem medicale 1891; 11:225-8.

2 O'Brien JR. Non-reactive tuberculosis. J Clin Pathol 1954;7:216-25.

3 Masud T, Kemp E. Corticosteroids in treatment of disseminated tuberculosis in patient with acquired immune deficiency syndrome. Am J Opthalmol 1986; 102:659-60.

4 Staples WP, Getaz EP, Botha D. Disseminated tuberculosis. Bone marrow necrosis and lymphoma-a case report. S Afr Med J 1977;52:680-3.

5 Montes M, Phillips C. Non-reactive tuberculosis. Am Rev Tuberc 1959;79:362-70.

6 Hansson V, Svane S, Torgerson O. Non-reactive tuberculosis and malignant blood disorders. J Oslo City Hosp 1972;22:5-15.

7 Paar J, Scheinman MM, Weaver RA. Disseminated nonreactive tuberculosis with basophilia, leukaemoid reaction and terminal pancytopenia. $N$ Engl J Med 1966; 274:335.

8 Proudfoot AT. Cryptic disseminated tuberculosis. $\mathrm{Br} \mathrm{J}$ Hosp Med 1971;5:773-80.

9 Lenzini L, Rottoli P, Rottoli L. The spectrum of human tuberculosis. Clin Exp Immunol 1977;27:230-7.

10 Holborow EJ, Reeves WG. Immunology in medicine. 1st ed. London: Academic Press, 1977:473-537.

11 Banyai AC. Diabetes and tuberculosis. Dis Chest 1959; 36:238-42.

12 Spain DM, Molumot N. Effect of cortisone on development of tuberculous lesions in guinea pigs and on their modification by streptomycin therapy. Am Rev Tuberc 1950;62:337.

13 Claman HN. Corticosteroids and lymphoid cells. $N$ Engl J Med 1972;287:388.

14 Ivanyi J. Pathogenic and protective interactions in Mycobacterium infections. In: Britten V, Hughes HPA, eds. Clinics in immunology and allergy. London: Saunders, 1986:127-57.

15 Brown CA, Brown IN. Mycobacterium bovis, BCG, modulation of murine antibody responses: influence of dose and degree of aggregation of live or dead organisms. Br J Exp Pathol 1982;63:133-43.

16 Rook GAW. Role of activated macrophages in the immunopathology of tuberculosis. Br Med Bull 1988; 44:611-23.

17 Lehmann V, Freudenburg MA, Galanos C. Lethal toxicity of lipopolysaccharide and tumour necrosis factor in normal and D-galactosamine treated mice. $J$ Exp Med 1987;165:657-63. 